\title{
When animal coloration is a poor match
}

\section{Tim Caro ${ }^{1}$ (D)}

Received: 7 June 2020 / Accepted: 26 September 2020 / Published online: 7 October 2020 (c) The Author(s) 2020

\begin{abstract}
Biologists usually pursue the adaptationist paradigm in trying to explain the functional significance of animal coloration. Here I collate instances in which coloration may be a poor match in the context of background matching, Batesian mimicry, aposematism, and colour polymorphisms. This can occur because of trade-offs with other functions, relaxed selection from predation, or colour trait neutrality. Also, mechanistic, pleiotropic and chance genetic effects can all result in a poor match to the background environment or to signaling efficiently. While biologists implicitly recognise these constraints placed on adaptive coloration, they rarely explicitly acknowledge the heterodox notion that coloration might be under weak selection or no selection at all. Unfortunately, it is difficult to show this definitively, as illustrated in an investigation into the function of colour polymorphisms in coconut crabs.
\end{abstract}

Keywords Background matching $\cdot$ Coconut crabs $\cdot$ Imperfect mimicry $\cdot$ Non-adaptive · Pleiotropy $\cdot$ Relaxed predation · Trade-offs

\section{Introduction}

For a century and a half biologists have been trying to understand the adaptive significance of animals' external appearances. They have explored the close fit between an animal's colour and its background (e.g., Endler 1984), the efficacy of coloration in signaling to conspecifics (e.g., Stuart-Fox et al. 2007) and to predators (e.g., Stevens and Ruxton 2012), and the way in which coloration influences heat load (e.g., Lindstedt et al. 2009) and protects against UV radiation (e.g., Jablonski and Chaplin 2000). Underpinning this enormous body of literature is an assumption that coloration is a good fit in the sense of being the best solution to a particular problem as far as mechanistic and phylogenetic constraints and competing selection pressures allow (Cuthill et al. 2017; Ruxton et al. 2018). But there are many situations in which we implicitly recognise that traits, in this case coloration, are a poor match to the task at hand (see discussion in Gould and Lewontin 1979; Stearns and Schmid-Hempel 1987). In this brief review, I first consider several different types of protective coloration and

Tim Caro

tmcaro@ucdavis.edu

1 School of Biological Sciences, University of Bristol, Bristol BS8 1TQ, UK 
remind readers that opposing selection pressures can result in instances in which coloration must be traded off against another benefit and therefore appear to be a poor fit. Second, I argue that there are cases in which external appearances are under relaxed selection and consequently that animals do not need to match their background particularly well. Third, broadening the argument beyond protective coloration, I discuss some proximate factors that force animals into signaling poorly to conspecifics. Last, I point to genetic phenomena that result in external appearances ill-suited to signaling and protective coloration. Empirically demonstrating that coloration has no immediate adaptive value is a serious challenge, however, and I highlight this difficulty using an example of colour polymorphism in coconut crabs (Birgus latro). My goal is to suggest that biologists begin to consider less than ideal coloration as a viable alternative to explaining certain types of coloration in some species, and some predictions are advanced as to the situations where this might occur. This proposal is not new: the idea that phenotypic traits may be selectively neutral has been examined in relation to systems other than coloration for many years (e.g., Orr 1998; Ho et al. 2017).

\section{Apparently poor protective coloration}

\section{Imperfect background matching}

Early biologists repeatedly drew attention to the close association between animals' external coloration and the colour of the background against which it is seen (e.g., Wallace 1889; Beddard 1892; Thayer 1909; Cott 1940). Endler (1978), however, realized that changing lighting conditions and moving between different environments constrains perfect background matching and suggested that concealing coloration represents a random sample of the background in which a prey animal experiences greatest predation pressure. This new view was subsequently challenged by models of individuals moving between different backgrounds (Merilaita et al. 1999; Houston et al. 2007) which showed that a specialist camouflage strategy on one background would provide little concealment on the other, so that a compromise strategy was optimal. Theoretically this could be achieved by target colours being intermediate between two backgrounds or by means of mixture methods in which discrete features of two backgrounds are used together (Hughes et al. 2019), ideas that have been addressed in experimental work (Merilaita and Lind 2005; Sherratt et al. 2007) but not satisfactorily shown to be operating in the sense of a single colour intermediary constituting an optimal solution. Possible examples of generalist background matching in the real world are currently scarce but include moths, butterflies, Aegean lizards (Podarcis erhardii), adult shore crabs (Carcinus maenas) (Hughes et al. 2019), and desert rodents (Nokelainen et al. 2020). Current thinking suggests that some species or individuals either employ specialist background matching whereas others employ generalist background matching (Duarte et al. 2016). If so, we should not be surprised to see some individuals poorly matched to a particular background on which they are encountered. Trade-offs within the context of maximizing protective coloration in heterogeneous environments, or between concealment and signaling, or between concealment and heat management may each result in a poor background fit. 


\section{Imperfect mimicry}

A separate but well-worked example of imperfect coloration concerns certain Batesian mimicry systems where harmless species poorly match the coloration and colour pattern of a well-defended model (Sherratt 2002). As an illustration, hoverflies are innocuous Diptera that visually mimic stinging Hymenoptera, yet to the human eye and that of pigeons (Columbia livia) the external appearances of some species sometimes resemble putative models weakly. Hypotheses to explain imperfect mimicry include compromise mimicry of several models (Edmunds 2000) or kin selection (Johnstone 2002) as based on a composite parameter of species abundance (Kikuchi and Pfennig 2013) but these explanations are difficult to substantiate. Instead, small-sized mimic species are more likely to visually diverge from models than larger mimic species presumably because they are less rewarding as prey and are therefore under relaxed selection from predatory attack (Penney et al. 2012). In another example, order of banding on coral snake mimics is irrelevant for persuading predators not to attack them because predator cognition is imprecise (Kikuchi and Pfennig 2010). In these examples, if precise colour patterns are the salient feature to which predators pay attention, the fit between the appearance of the mimic and the model appears poor, although not if they focus on coloration per se.

\section{Frequency dependent colour polymorphism}

Another way in which individuals may be poorly matched to their background is if selection by predators drives prey individuals to appear dissimilar to conspecifics in the population (Ford 1945). When predators use search images to discover prey items, predators may concentrate on common prey forms. As a consequence, rarer prey colour morphs will be taken less than expected from their abundance in the population and will prosper (Gibb 1962). Such disruptive selection can occur in cryptic prey populations, so the rarer morph must simply look different from the common morph and not necessarily match its background to escape predators' attention (Allen 1988). A similar phenomenon is seen under reflexive selection where every individual looks slightly different from every other one (Owen and Whiteley 1986).

\section{Looking different from cryptic prey}

For aposematic species considerable research tried to understand the extent to which internal contrast, contrast against the background, colour and colour combinations and pattern alter the speed of predator learning about aposematic prey; how distinctiveness and contrast enhance prey recognition; and how distinctiveness, particular colours and toxicity each affect predators' memories of distasteful prey (Ruxton et al. 2018). In essence, these studies investigate how prey maximize efficacy of advertising distastefulness to receivers. Using human subjects catching artificial prey on a computer screen, however, Sherratt and Beatty (2003) demonstrated that reliably defended prey will be avoided simply as long as they have an appearance distinct from cryptic prey; they do not have to be particularly conspicuous. A possible example are ithomine butterflies that are highly unpalatable but appear more distinctive than conspicuous (Mallet and Singer 
1987). In short, defenses may be advertised without the advertisement necessarily being maximally effective but simply different from the cryptic morph.

\section{Avoiding sensory bias}

A fifth situation in which coloration may be poorly matched is when there is selection on prey to avoid the visual bias of predators. Predators' visual systems are tuned to certain spectral sensitivities and prey items whose external appearances reflect at wavelengths that differ from these will more difficult to see. To escape the attention of predators, male Trinidadian guppies (Poecilia reticulata) living in predator-rich streams have bellies that are only weakly orange even though orange is the colour most preferred by females (Ruell et al. 2013). In this instance there is selection pressure to avoid being detected by predators rather than selection based on maximizing signal efficacy directed at conspecifics. Another example are unripe fruits pigmented with green chlorophyll that not to match background leaf coloration well but are simply less red than ripe fruit that can be easily seen by primate dispersers (Schaefer and Schaefer 2007).

These five sections involving different mechanisms of protective coloration demonstrate that coloration does not necessarily have to solve the biological problem that the observer first proposed (Maynard Smith 1978). I next turn to ecological circumstances in which animals are not under strong selection to be cryptic.

\section{Relaxed selection on protective coloration}

Protective coloration is mediated by the environmental medium through which predators see prey and by the predator's visual senses (Endler 1990). In situations in which predators are unable to see prey easily, selection on fine-tuned protective coloration may be relaxed. For example, in circumstances where light levels are low or non-existent, we can expect that prey will match their background poorly or not at all. Examples are depigmented cave-dwelling troglobites that include molluscs, arachnids, millipedes, crustacea, insects, fish, salamanders and snakes (Gross and Wilkens 2013). Also, species that are fossorial which come to the surface rarely, such as mole species and naked mole-rats (Heterocephalus glaber), live in habitats devoid of light and should therefore experience relaxed selection on protective coloration. Nonetheless brief periods of time above ground may still shape external coloration to some degree (Braude et al. 2001). Yet another class of prey subject to weak selection on coloration are species that inhabit refuges or that can rapidly retreat into holes. Abdomens of hermit crabs housed in mollusc shells are depigmented, as are marine annelid worm species that can retreat into a burrow. Fourth, appearances of benthic species are relatively poor matches to the substrates against which they are viewed. Estimates of the contrast sensitivity of deep-sea visual systems suggest that even approximate matches may be sufficient for crypsis in visually complex benthic habitats (Johnsen 2005).

A second category of prey subject to relaxed selection are species that are very large and hence relatively immune from predation such as adult African elephants (Loxodonta africana), white rhinoceroses (Ceratotherium simum) and baleen whales, which are unlikely to be under selection to match their background precisely (Owen-Smith 1988). 


\section{Mechanistic factors}

Imprecise protective coloration can result from mechanistic constraints. For example, when external coloration is mediated by blood flow through epidermal capillaries, the colour will be less saturated in cold weather, in circumstances in which blood is shunted to muscles during flight from a predator, when the individual is anemic due to sickness, or as a result of stress or fear when blood is shunted to other organs. In circumstances where external coloration is due to pigmentation, carotenoid production is directly influenced by dietary carotenoid intake resulting in reduced signaling ability that may influence the amount of red and orange in sexual (Moller et al. 2000) or aposematic signals (Mochida et al. 2013). Although carotenoid concentrations in the integument may in some cases be honest signals of condition, they operate poorly from a signaling perspective.

\section{Genetic reasons}

Aspects of coloration may be constrained by pleiotropy during development (Roulin 2004). For example, production of melanin pigment has many ancillary effects including heightened sexual activity, aggressiveness and increased body size that may themselves be under selection, so that optimal eumelanin production for background matching in shady or burnt habitats may be altered (Ducrest et al. 2008).

Founder effects or genetic drift may also be responsible for poor fits between coloration and the habitat in which the animal lives. Peres and colleagues (1996) reported that saddleback tamarin (Saguinus fuscicollis) populations have very different pelage hues on each side of major Brazilian rivers despite the rainforest habitat being identical. The rivers are too wide to be traversed by this small monkey and it seems probable that eumelanin and phaeomelanin production in hair follicles are differentially favoured as a result of chance genetic events or genetic drift on each side of the barrier. The species apparently does not match its background perfectly on both sides of the rivers.

\section{Proving a negative}

The difficulty in demonstrating that coloration might not be subject to direct selection in order to signal effectively, or to effect protection, is with what it should be compared (Pierce and Ollason 1987). Modeling background matching with quantitative measures of the background, the organism, and knowing the spectral sensitivity of the most effective predator(s) (Stevens et al. 2007; Troscianko and Stevens 2015) may still generate a far from perfect fit with the background. Does this mean that trade-offs or pleiotropy are involved? If external coloration is manifested as a pleiotropic effect of selection on other traits, for example, it is encumbant on the researcher to first explore several different candidate functions including background matching, signaling to predators, sexual signaling and temperature regulation and to find no selective benefits with regard to coloration per se. Second, the mechanism producing poor coloration needs to be identified such as reduction in pigmentation due to poor diet or the underlying genetic mechanism. A comprehensive investigation of the adaptive significance of colour polymorphism therefore involves 
systematically exploring different functional hypotheses and finding each to be wanting to accept that coloration is not being directly acted on by selection, and to identify the mechanism (Fincke 1994). I illustrate this with a recent study of coconut crabs.

\section{Coconut crab colour polymorphism}

In many parts of their range, coconut crabs are found in two colour morphs (Nokelainen et al. 2018). One has a red carapace usually with a white ventrum, the other has a blue carapace with a blue ventrum; occasionally ventra of the red morph are tinged with blue (Fig. 1). On some island complexes across their Indian Ocean and western Pacific Ocean range, however, only red or only blue morphs are encountered but not both. Adult and juvenile coconut crabs have no predators: they are the world's largest land crab (Laidre 2018) with extremely powerful claws (Oka et al. 2016) and are an apex predator on some islands (Laidre 2017). This might suggest they are not under strong selection to be cryptic to predators. The species is principally nocturnal suggesting that aposematic or intraspecific signaling is muted, while nocturnality and lack of nighttime ultraviolet radiation suggests that they are not using carapace pigmentation for heat management or UV protection. Coconut crabs mate very rapidly on land with apparently little mate choice involved (Helfman 1977a) suggesting coloration is unlikely to be involved in mate choice. They deposit their

Fig. 1 Red (above) and blue (below) coconut crabs (photographs by Tim Caro)
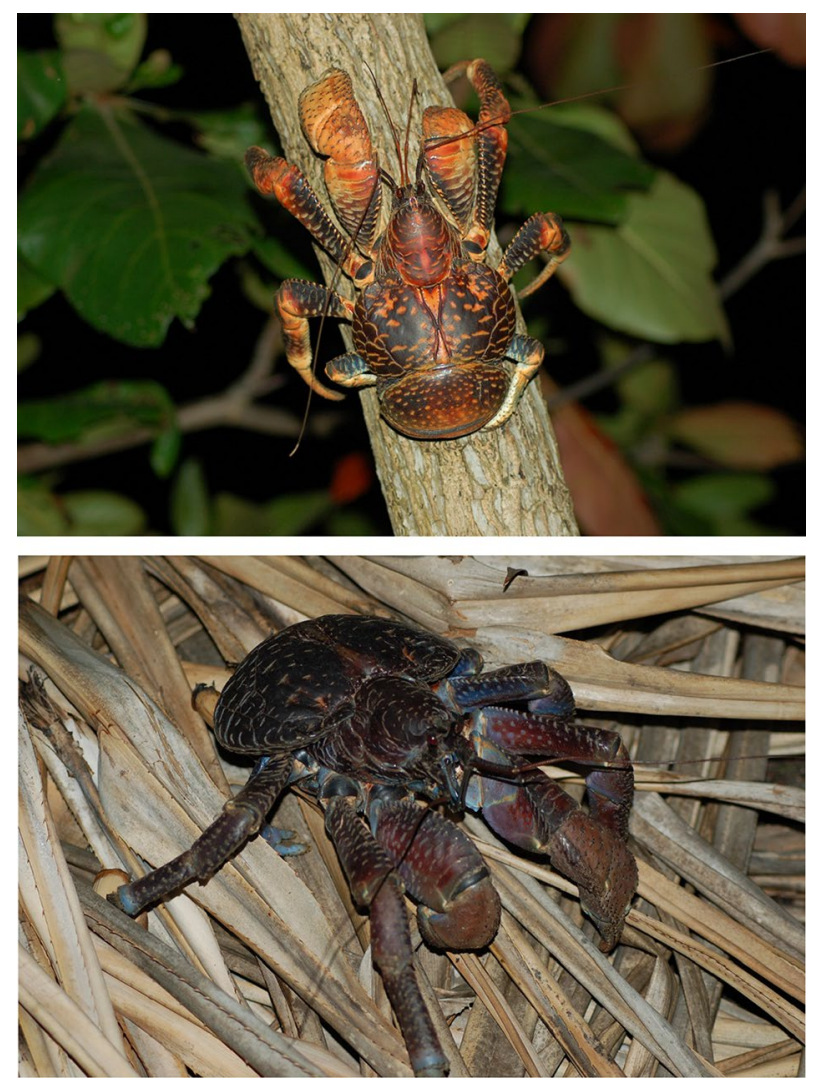
fertilized eggs at sea making it extremely difficult to track offspring or monitor reproductive success.

A polymorphism is defined as "two or more well-marked forms capable of appearing among the offspring of a single female, and occurring with frequencies high enough to exclude the maintenance of the rarest of them by recurrent mutation" (Ford 1945). If colour polymorphism was under natural selection, one would predict that there should be different context-specific advantages for each morph. If morphs were subject to differential mate choice, one might expect to see sex or age or dominance associations. If coloration resulted from pleiotropy one might expect colour morph-specific associations with naturally selected behavioural, physiological or morphological traits.

To investigate these alternatives, we caught and then released free-living coconut crabs on the Zanzibari archipelago, Tanzania and nearby islands. We examined whether coconut crab morphs differed by sex or age but there were no associations (Table 1; see also Nokelainen et al. 2018; Caro and Morgan 2018) suggesting their appearance is not sexually selected. Morphs did not differ on six body linear dimensions including span of their third legs used to tap opponents at the start of aggressive encounters (Helfman 1977b) (Table 1) suggesting coloration is not a means of intrasexual signaling or linked pleiotropically to body size. Additionally, colour morphs did not differ in measures of robustness, strength or body temperature (Table 1) to which coloration might be pleiotropically related.

Coconut crab colour morphs are found together in the same area at the same time (Caro et al. 2019) and the proportion of instances that we encountered them did not differ by habitat type (respectively red $(\mathrm{N}=450$ sightings) and blue $(\mathrm{N}=143)$ : open $25.1,25.9 \%$, edge $15.1,15.4 \%$, thin canopy $30.9,30.1 \%$, thick canopy $\left.28.9,28.7 \% ; \mathrm{X}_{3}{ }^{2}=0.056, p=0.997\right)$. The proportions of each morph encountered did not differ significantly according to degree of moonlight $(32.3 \%$ of red $(\mathrm{N}=495)$ and $24.7 \%$ of blue $(\mathrm{N}=158)$ morphs were found on lighter nights, defined as nights $10-19$ following the new moon, $\mathrm{X}_{1}^{2}=3.299, p=0.069$ ). Proportions of red and blue morphs did not change over a 4-year period of time (red $(\mathrm{N}=490)$ and blue $(\mathrm{N}=154)$ respectively: 2016: 6.7, 8.4\%; 2017: 26.7, 30.5\%; 2018: 33.9, $37.0 \%$; 2019: $32.7,24.1 \% ; \mathrm{X}_{3}^{2}=4.269, p=0.234$ ) suggesting we were not witnessing a snapshot of evolutionary change over time.

Observations of free-living crabs showed no differences in patterns of movement, and experiments revealed no differences in emergence times from a holding bucket, willingness to grasp objects, exploratory movements, or behavioural disposition along a shy-bold continuum (Table 1) (Caro and Morgan 2018; Caro et al. 2019) suggesting no pleiotropic linkages with at least some facets of behaviour.

These findings suggest that morph coloration is not associated with differences in life history, is not indicative of size or sturdiness, and is not linked to behaviour; that morphs do not differentially occupy different areas or microhabitats, and that their prevalence is not undergoing temporal changes at least over a short time scale. Their size and weaponry suggest they suffer little predation as adults, and studies elsewhere attest to this (Drew et al. 2010); rapid mating suggests little mate choice; and their nocturnal lifestyle suggests signaling to conspecifics or heterospecifics is unlikely.

Instead, our current supposition is that red and blue carapace coloration is caused by simple Mendelian genetics because the ratio of red:blue is invariably 3:1 where they cooccur (Caro and Morgan 2018), although the occasional presence of intermediately coloured individuals with brown-purple carapaces hints that it may be more complicated. The underlying genetics are currently under investigation. While the working hypothesis that carapace coloration is a neutral trait linked to an, as yet, unspecified pleiotropic trait that is under selection, additional investigations are required. Nevertheless, this case study 


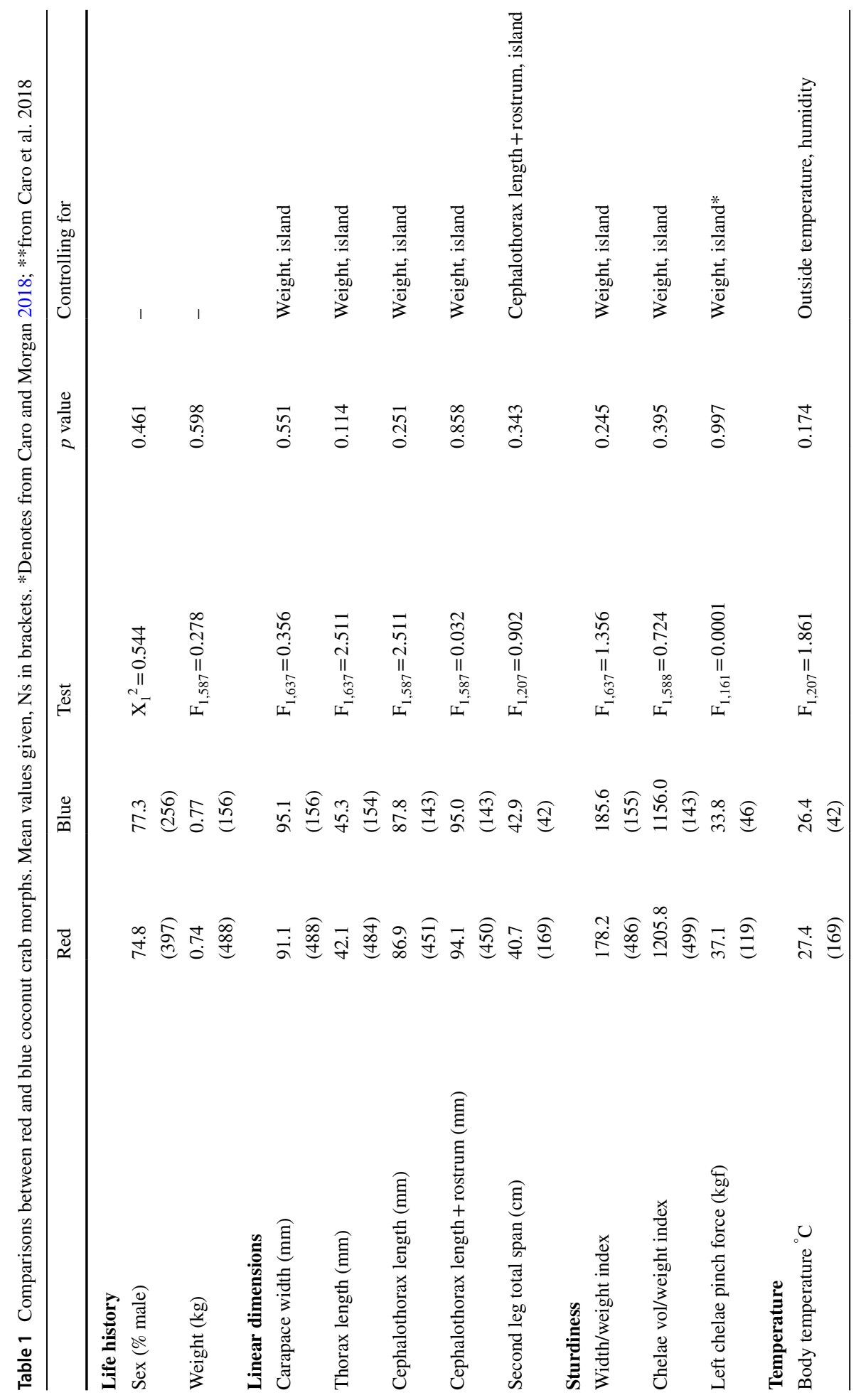




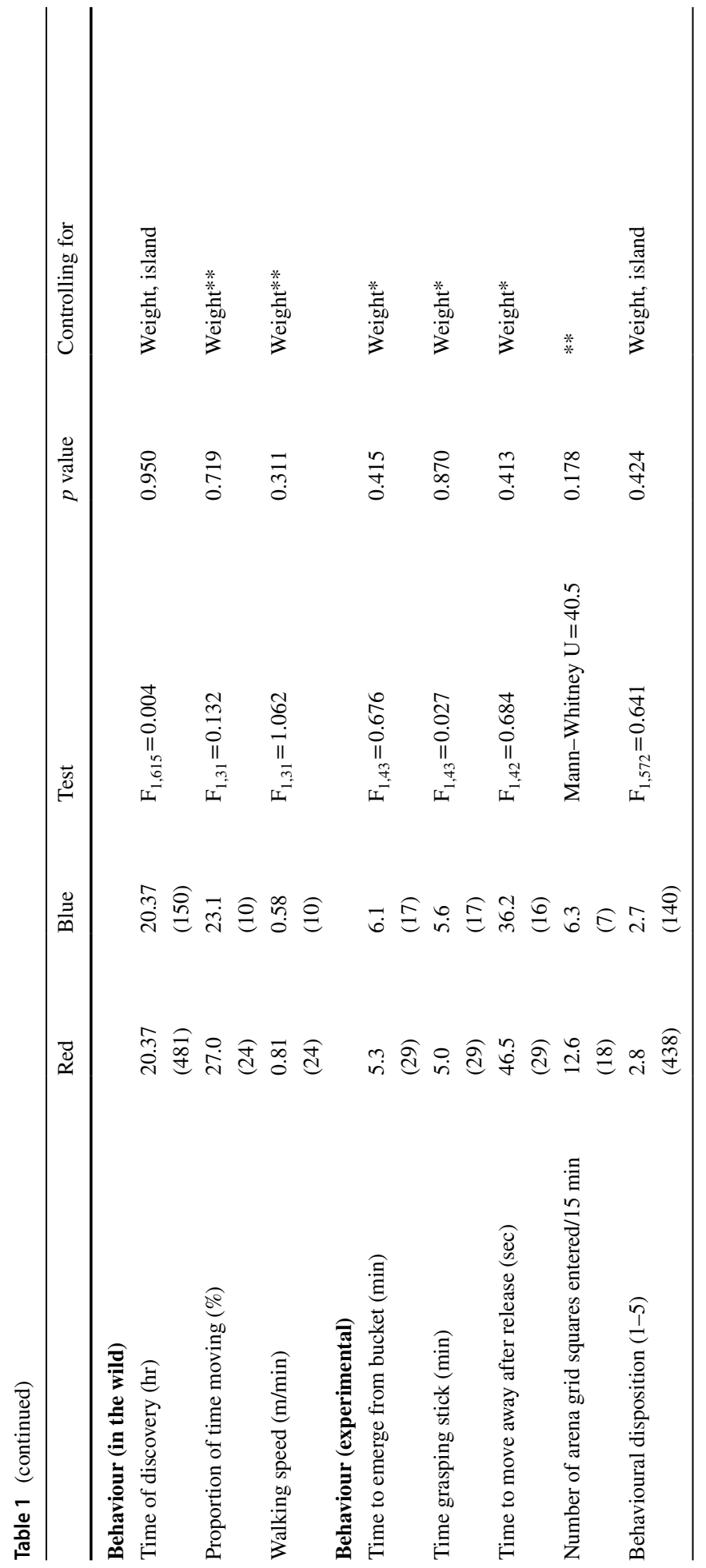


highlights the numerous steps required to demonstrate that coloration is non-adaptive (see also Fincke 1994).

\section{Predictions}

If colour evolution is to be viewed as imperfect in some circumstances but not in others, it would be helpful to identify the situations in which this might occur. In regards to cryspsis, we would expect poor background matching in species or life stages in which individuals move between different environments and where a specialist fit between the external appearance and one particular background is disadvantageous. Second, we can envisage poor background matching in species which are subject to several equally important predators wth different visual systems. For example, modelling shows that weak signaling of aposematic species can evolve if predators vary in their tendency to attack defended prey (Endler and Mappes 2004). Additionally, aposematism may be effective against a smaller predator species or one susceptible to toxins but not to a larger predator where crypsis might be more effective. This will set up a trade-off in the optimal form of protective coloration.

In Batesian mimicry systems we might expect certain aspects of the appearance to mimic the model well but other aspects to mimic it imprecisely if predators focus on either patterns or morphological traits such as location or length of appendanges, rather than on colour per se when deciding to attack. In polymorphic species, less than perfect protective coloration can be expected since each morph gains advantages from simply looking different from the other.

In regards to ecological predictions, species inhabiting poorly lit habitats undergound, in caves, or in the deep sea are not anticipated to match their background well compared to species living in well-lit open habitats. Similarly, species living in shelters such as bivalve molluscs may be under less selection to be protectively colored (Williams 2017). Very large species are not expected to be under strong selection for crypsis.

In regards to mechanism, where coloration is mediated by blood flow, individuals can be expected to vary greatly in their ability to signal effectively. Where coloration is mediated by melanin we should envisage ancillary selection pressures moulding the extent of melanization since melanin has protective and anti-bacterial properties, and is also linked to testosterone production (Bokony et al. 2008). This then is a non-exhaustive list of the situations where coloration may not be the solution to the problem that we initially believed must be solved.

\section{Outstanding questions}

Allowing that there is a continuum of perfection in external appearance with some forms of coloration perfectly matching their background (e.g., some octopus species), through to being imperfect (e.g., hoverfly mimicry), through to relaxed selection (e.g., cavefish), to being selectively neutral demands a more nuanced way of viewing animal coloration. More specifically we must first agree on the criteria needed to accept this heterodox position. Do functional considerations regarding coloration, namely defense mechanisms, sexual selection, intraspecific signaling, temperature management and UV protection all have to be explored first? And if so, how thoroughly? What constitutes negative evidence: proximate 
measures or lifetime reproductive success associated with natural coloration, or is experimental manipulation necessary or sufficient? These fundamental questions are reminiscent of trying to show that alternative reproductive strategies have equal fitness pay-offs (Gross 1996). Second, is it necessary to demonstrate genetically that coloration is driven by pleiotropic alleles or can we assume this from phenotypic associations alone? If different degrees of poorly adapted explanations for coloration are to be taken seriously, these questions need more thought and consensus by those interested in the evolution of animal coloration.

Acknowledgements I thank Tom Sherratt for very helpful suggestions, and Brock Fenton and an anonymous reviewer for comments.

\section{Compliance with ethical standards}

Conflict of interest The author declares no conflict of interest.

Open Access This article is licensed under a Creative Commons Attribution 4.0 International License, which permits use, sharing, adaptation, distribution and reproduction in any medium or format, as long as you give appropriate credit to the original author(s) and the source, provide a link to the Creative Commons licence, and indicate if changes were made. The images or other third party material in this article are included in the article's Creative Commons licence, unless indicated otherwise in a credit line to the material. If material is not included in the article's Creative Commons licence and your intended use is not permitted by statutory regulation or exceeds the permitted use, you will need to obtain permission directly from the copyright holder. To view a copy of this licence, visit http://creativecommons.org/licenses/by/4.0/.

\section{References}

Allen JA (1988) Frequency-dependent selection by predators. Phil Trans Roy Soc B 319:485-503.

Beddard FE (1892) Animal coloration: an account of the principal facts and theories relating to the colours and markings of animals. S. Sonnenschein and Company, London

Bókony V, Garamszegi LZ, Hirschenhauser K, Liker A (2008) Testosterone and melanin-based black plumage coloration: a comparative study. Behav Ecol Sociobiol 62:1229

Braude S, Ciszek D, Berg NE, Shefferly N (2001) The ontogeny and distribution of countershading in colonies of the naked mole-rat (Heterocephalus glaber). J Zool Lond 253:351-357

Caro T, Morgan VM (2018) Correlates of colour polymorphism in coconut crabs Birgus latro. Zoology $129: 1-8$

Caro T, Cluff E, Morgan VM (2019) Colour polymorphism and protective coloration in coconut crabs. Ethol Ecol Evol 2019:514-525

Cott HB (1940) Adaptive colouration in animals. Metheun, London

Cuthill IC et al (2017) The biology of color. Science 357:eaan0221

Drew MM, Harzsch S, Stensmyr M, Erland S, Hansson BS (2010) A review of the biology and ecology of the robber crab, Birgus latro (Linnaeus, 1767)(Anomura: Coenobitidae). Zoologisch Anzeiger-A J Comp Zool 249:45-67

Duarte RC, Stevens M, Flores AA (2016) Shape, colour plasticity, and habitat use indicate morph-specific camouflage strategies in a marine shrimp. BMC Evol Biol 16:218

Ducrest AL, Keller L, Roulin A (2008) Pleiotropy in the melanocortin system, coloration and behavioural syndromes. Trends Ecol Evol 23:502-510

Edmunds M (2000) Why are there good mimics and poor mimics? Biol J Linn Soc 70:459-466

Endler JA (1978) A predator's view of animal color patterns. In: Hecht MK, Steere WC, Wallace B (eds) Evolutionary biology evolutionary biology. Springer, Boston, pp 319-364

Endler JA (1984) Progressive background in moths, and a quantitative measure of crypsis. Biol J Linn Soc 22:187-231

Endler JA (1990) On the measurement and classification of colour in studies of animal colour patterns. Biol J Linn Soc 41:315-352 
Endler JA, Mappes J (2004) Predator mixes and the conspicuousness of aposematic signals. Amer Nat $163: 532-547$

Fincke OM (1994) Female colour polymorphism in damselflies : failure to reject the null hypothesis. Anim Behav 47:1249-1266

Ford EB (1945) Polymorphism. Biol Rev 20:73-88

Gibb JA (1962) L. Tinbergen's hypothesis of the role of specific search images. Ibis 104:106-111

Gould SJ, Lewontin RC (1979) The spandrels of San Marco and the panglossian paradigm: a critique of the adaptationist programme. Proc Roy Soc Lond 205:581-598

Gross MR (1996) Alternative reproductive strategies and tactics: diversity within sexes. Trends Ecol Evol 11:92-98

Gross JB, Wilkens H (2013) Albinism in phylogenetically and geographically distinct populations of astyanax cavefish arises through the same loss-of-function Oca2 allele. Heredity 111:122-130

Helfman GS (1977a) Copulatory Behavior of the Coconut or Robber Crab Birgus Latro (L.)(Decapoda Anomura, Paguridea, Coenobitidae) 1. Crustaceana 33:198-202

Helfman GS (1977b) Agonistic Behaviour of the Coconut Crab, Birgus latro (L.) 1. Zeit Tierpsychol 43:425-438

Ho W-C, Ohya Y, Zhang J (2017) Testing the neutral hypothesis for phenotypic evolution. Proc Nat Acad Sci 114:12219-12224

Houston AI, Stevens M, Cuthill IC (2007) Animal camouflage: compromise or specialize in a 2 patchtype environment? Behav Ecol 18:769-775

Hughes A, Liggins E, Stevens M (2019) Imperfect camouflage: how to hide in a variable world? Proc Roy Soc B 286:20190646

Jablonski NG, Chaplin G (2000) The evolution of human skin coloration. J Human Evol 39:57-106

Johnsen S (2005) The red and the black: bioluminescence and the color of animals in the deep sea. Integr Comp Biol 45:234-246

Johnstone RA (2002) The evolution of inaccurate mimics. Nature 418:524-526

Kikuchi DW, Pfennig DW (2010) Predator cognition permits imperfect coral snake mimicry. Amer Natur 176:830-834

Kikuchi DW, Pfennig DW (2013) Imperfect mimicry and the limits of natural selection. Q Rev Biol $88: 297-315$

Laidre ME (2017) Ruler of the atoll: the world's largest land invertebrate. Frontiers Ecol Environ $15: 27-528$

Laidre ME (2018) Coconut crabs. Curr Biol 28:R58-R60

Lindstedt C, Lindström L, Mappes J (2009) Thermoregulation constrains effective warning signal expression. Evolution 63:469-478

Mallet J, Singer MC (1987) Individual selection, kin selection, and the shifting balance in the evolution of warning colours: the evidence from butterflies. Biol J Linn Soc 32:337-350

Maynard Smith J (1978) Optimization theory in evolution. Ann Rev Systemat Ecol 9:31-56

Merilaita S, Lind J (2005) Background-matching and disruptive coloration, and the evolution of cryptic coloration. Proc Roy Soc B 272:665-670

Merilaita S, Tuomi J, Jormalainen V (1999) Optimization of cryptic coloration in heterogeneous habitats. Biol J Linn Soc 67:151-161

Mochida K, Kitada M, Ikeda K, Toda M, Takatani T, Arakawa O (2013) Spatial and temporal instability of local biotic community mediate a form of aposematic defense in newts, consisting of carotenoidbased coloration and tetrodotoxin. J Chem Ecol 39:1186-1192

Moller AP, Biard C, Blount JD, Houston DC, Ninni P, Saino N, Surai PF (2000) Carotenoid-dependent signals: indicators of foraging efficiency, immunocompetence or detoxification ability? Poult Avian Biol Rev 11:137-160

Nokelainen O, Stevens M, Caro T (2018) Colour polymorphism inthe coconut crab (Birgus latro). Evol Ecol 32:75-88

Nokelainen O, Brito JC, Scott-Samuel NE, Valkonen JK, Boratyński Z (2020) Camouflage accuracy in Sahara-Sahel desert rodents. J Anim Ecol. https://doi.org/10.1111/1365-2656.13225

Oka SI, Tomita T, Miyamoto K (2016) A mighty claw: pinching force of the coconut crab, the largest terrestrial crustacean. PLoS ONE 11:e0166108

Orr HA (1998) Testing natural selection vs genetric drift in phenotypic evolution using quantitative trait locus data. Genetics 149:2099-2104

Owen DF, Whiteley D (1986) Reflective selection: moment's hypothesis resurrected. Oikos 47:117-120

Owen-Smith RN (1988) Megaherbivores: the influence of very large body size on ecology. Cambridge University Press, Cambridge 
Penney HD, Hassall C, Skevington JH, Abbott KR, Sherratt TN (2012) A comparative analysis of the evolution of imperfect mimicry. Nature 483:461

Peres CA, Patton JL, da Silva MNF (1996) Riverine barriers and gene flow in Amazonian saddle-back tamarins. Folia Primatol 67:113-124

Pierce GJ, Ollason JG (1987) Eight reasons why optimal foraging theory is a complete waste of time. Oikos 49:111-118

Roulin A (2004) The evolution, maintenance and adaptive function of genetic colour polymorphism in birds. Biol Rev 79:815-848

Ruell EW, Handelsman CA, Hawkins CL, Sofaer HR, Ghalambor CK, Angeloni L (2013) Fear, food and sexual ornamentation: plasticity of colour development in trinidadian guppies. Proc Roy Soc B 280:20122019

Ruxton GD, Allen WL, Sherratt TN, Speed MP (2018) Avoiding attack: the evolutionary ecology of crypsis, aposematism, and mimicry. Oxford University Press, Oxford

Schaefer HM, Schaefer V (2007) The evolution of visual fruit signals: concepts and constraints. In: Dennis AJ, Green RJ, Schupp EW, Westcott DA (eds) Seed dispersal: theory and its application in a changing world. CABI, Oxfordshire, pp 59-77

Sherratt TN (2002) The evolution of imperfect mimicry. Behav Ecol 13:821-826

Sherratt TN, Beatty CD (2003) The evolution of warning signals as reliable indicators of prey defense. Amer Nat 162:377-389

Sherratt TN, Pollitt D, Wilkinson DM (2007) The evolution of crypsis in replicating populations of webbased prey. Oikos 116:449-460

Stearns SC, Schmid-Hempel P (1987) Evolutionary insights should not be wasted. Oikos 49:118-125

Stevens M, Ruxton GD (2012) Linking the evolution and form of warning coloration in nature. Proc Roy Soc B 279:417-426

Stevens M, Párraga CA, Cuthill IC, Partridge JC, Troscianko TS (2007) Using digital photography to study animal coloration. Biol J Linn Soc 90:211-237

Stuart-Fox D, Moussalli A, Whiting MJ (2007) Natural selection on social signals: signal efficacy and the evolution of chameleon display coloration. Amer Nat 170:916-930

Troscianko J, Stevens M (2015) Image calibration and analysis toolbox-a free software suite for objectively measuring reflectance, colour and pattern. Methods Ecol Evol 6:1320-1331

Thayer GH (1909) Concealing-coloration in the animal kingdom: being a summary of Abbott H. Thayer's discoveries, New York

Wallace AR (1889) Darwinism, an exponent of the theory of natural selection, with some of its applications. Macmillan Co, London

Williams ST (2017) Molluscan shell colour. Biol Rev 92:1039-1058

Publisher's Note Springer Nature remains neutral with regard to jurisdictional claims in published maps and institutional affiliations. 